\title{
Invasive Fungal Sinusitis: Common Imaging Findings and Co-Relation with Intraoperative Features; A Retrospective Multi-Institutional Analysis and Review of Literature
}

\author{
Diptarka Bhattacharyya and Abhishek Ramadhin* \\ Sinai Hospital, USA
}

Submission: July 18, 2018; Published: July 27, 2018

*Corresponding author: Abhishek Kumar Ramadhin, Rhinology fellow, Sinai Hospital, Baltimore, USA, Tel: 4049555906; Email: drabhishekkumar4u@gmail.com

\section{Introduction}

In the last century, Acute Invasive Fungal Sinusitis has become increasingly recognized as an important entity, as, although uncommon, it has a rapid clinical course and high morbidity and mortality. Moreover, due to the rarity of the disease, treatment and diagnostic controversies still exist. It is most commonly seen in immunocompromised individuals although there are reported cases occurring in people without immune deficiency too [1]. One of the more challenging aspects in the management of this disease is early diagnosis, as the clinical symptoms can be myriad, the imaging findings are nonspecific and subtle, and nasal endoscopy may often show only mucosal pallor or even normal mucosa in the early stages. This study aims to assess the imaging findings commonly found in these patients, and the correlation with intraoperative findings, and see if the combination of both can improve the diagnostic yield, and also review the existing literature regarding the same.

\section{Materials and Methods}

This study is an anonymized, multi institutional retrospective study undertaken in two large tertiary referral centers, whereby patient records and data from 2007 to 2017 were systematically reviewed, and patients meeting the inclusion criteria were selected. The data was assessed regarding specifically the initial imaging study, either CT scan or MRI or both, and the first nasal endoscopy report was reviewed for the findings in patients of Invasive fungal sinusitis and statistical analysis done. A literature review was conducted, and a comparative analysis done. Institutional IRB approval was obtained prior to this (ENT/ECARP/14/63).

Inclusion Criteria: As this is a retrospective study, the criteria were:

a. Proven fungal tissue invasion noted on tissue samples irrespective of eventual fungal culture results. b. Patients who did undergo either Contrast enhanced CT scan or MRI of the Paranasal sinuses, orbit with or without brain.

c. Duration of symptoms less than 1 month at the time of first presentation to the study center.

d. Follow up of 6 months or known disease specific outcome.

\section{Exclusion Criteria}

Patients who had symptoms greater than 3 months at initial presentation to the study center, or patients whose tissue biopsy showed granulomatous inflammation and fibrosis. Any studies done AFTER the first endoscopic exam were NOT included in this study, as that would not fit into the criteria of early prediagnostic imaging finding that this study is specific to. At our institute, the initial imaging study of choice is a Contrast enhanced CT scan, for various reasons like cost and availability, and MRI is reserved for frank extra sinus spread on clinical exam or suspicion of same on CT scan.

\section{The Imaging Study Reports Were Assessed for Specific Criteria}

a) On CT Scan: unilateral, asymmetric soft tissue thickening, bone erosion, and extra sinus extension

b) On MRI Scan: Loss of contrast enhancement (LoCE) of the nasal mucosa, Peri-antral fat stranding, frank intra orbital disease and other findings of intracranial spread (intracranial abscess, Cavernous sinus thrombosis).

The findings were then compared with the initial endoscopic exam findings and the correlation noted. All the patients in the above study were treated with multi-modality treatment, which included systemic antifungal treatment, i.e. Intravenous Amphotericin B $(1.5 \mathrm{mg} / \mathrm{kg} /$ day in patients receiving regular Amphotericin $B$ and $5 \mathrm{mg} / \mathrm{kg} /$ day in patients receiving 


\section{Global Journal of Otolaryngology}

liposomal Amphotericin B)16 with additional oral voriconazole added to patients diagnosed with aspergillus species as the causative agent $[2,4]$, local amphotericin irrigation daily and nasal debridements every week [2,3] Liposomal Amp B was reserved for patients who had toxicities from D Ampho B, and Voriconazole was added for patients who had Aspergillus as the causative agent (Figures 1\& 2).

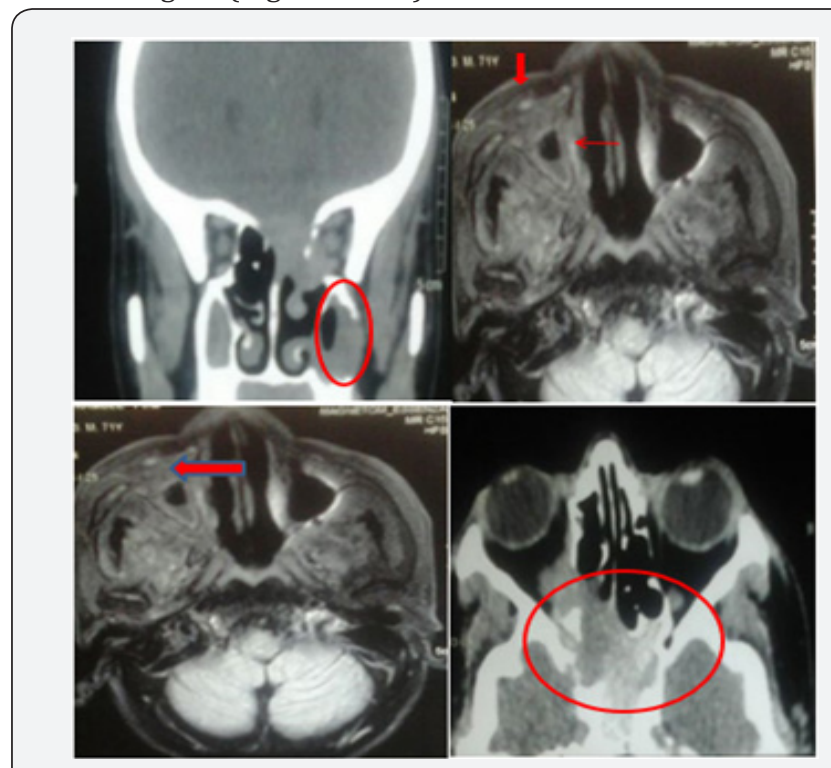

Figure 1: Common Imaging findings in Invasive Fungal Sinusitis (Clockwise From top): A: CT scan coronal showing asymmetric soft tissue thickening; B: MRI T1 showing LoCE (thin arrow) and subtle premaxillary fat stranding (thick arrow); C: MRI T1 demonstrating LoCE in the sinus mucosa; D: CT scan showing posterior disease with bone erosion and orbital apex involvement.

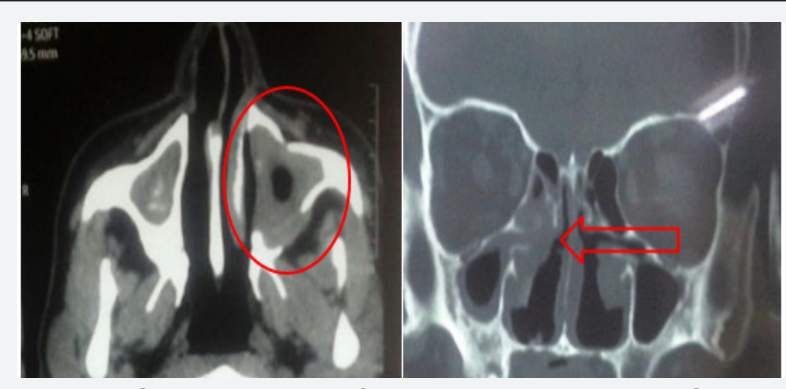

Figure 2: Common Imaging findings in Invasive Fungal Sinusitis continued: CT scan axial showing soft tissue thickening in the maxillary sinus (Left); and soft tissue thickening of lateral nasal wall (Right).

Results

Table 1: Demographic details of study group.

\begin{tabular}{|c|c|c|c|c|}
\hline & & Males & Females & total \\
\hline Patient(n) & & 24 & 17 & 41 \\
\hline \multicolumn{2}{|c|}{ Age (Median) } & $64(45-83)$ & $58(49-78)$ & $\mathrm{x}$ \\
\hline \multicolumn{2}{|c|}{ Comorbidity } & & & \\
\hline & Diabetes & 15 & 11 & 26 \\
\hline & Malignancy & 6 & 4 & 10 \\
\hline & Transplant & 3 & 2 & 5 \\
\hline
\end{tabular}

Table 2: Pathogen distribution.

\begin{tabular}{|c|c|c|}
\hline Pathogen & Diabetic & Total \\
\hline Mucor $s p p$ & 13 & 19 \\
\hline Aspergillus & 10 & 17 \\
\hline Fusarium & 1 & 1 \\
\hline Candida & 2 & 2 \\
\hline
\end{tabular}

Table 3: Orbital findings in patients in the study group.

\begin{tabular}{|c|c|}
\hline Symptom & no. of patients \\
\hline Chemosis & 11 \\
\hline Proptosis & 10 \\
\hline Opthalmoplegia & 3 \\
\hline Dimunition of vision & 3 \\
\hline Retro-orbital pain & 7 \\
\hline
\end{tabular}

Table 4: Imaging findings in patient group.

\begin{tabular}{|c|c|}
\hline Imaging finding & No. of patients \\
\hline $\begin{array}{c}\text { CT scan } \\
\text { Unilateral, asymmetric soft tissue } \\
\text { thickening }\end{array}$ & 37 \\
\hline Bone erosion & 15 \\
\hline Extra sinus Spread & 7 \\
\hline MRI Scan & 13 \\
\hline $\begin{array}{c}\text { Loss of Contrast Enhancement } \\
\text { (LoCE) }\end{array}$ & 8 \\
\hline Periantral fat stranding & 6 \\
\hline Intra orbital involvement & 2 \\
\hline Intracranial involvement & \\
\hline
\end{tabular}

A total of 41 patients were found to meet the criteria for the study. The demographic data, co-morbid conditions, causative organism can be found in Tables $1 \& 2$. As expected Diabetes Mellitus was the commonest underlying condition identified in 23 of the patients (63.4\%). The commonest organism identified was Mucor or Rhizopus, which was found to be more prevalent in Diabetics. As per institutional protocols, all 41 patients had undergone CT scan initially, with 17 patients also having undergone concomitant MRI of the Paranasal sinus and orbit. Out of these, 13 patients had clinical symptoms of orbital involvement (Table 3) and 4 patients had immediate MRI done because of suspicion of extra sinus spread on initial CT scan. The commonest abnormal finding on CT scan (Table 4) was unilateral or asymmetric soft tissue swelling which was found to be present on 37 out of 41 scans reviewed. Bony erosion was noted in 15 patients and frank extra sinus disease was noted on 7 scans. Although other studies have previously further subdivided the soft tissue swelling into nasal vs sinus components, this was not found to add any extra information in those studies, and hence it was not done [5]. The MRI scans (Table 4) were assessed for Loss of Contrast Enhancement (LoCE) which was present in 13 out of 17 scans, being the commonest abnormal finding. Periantral fat stranding was noted in 8 of 17 scans, frank intra orbital disease was present in 6 scans and intracranial findings were noted in 
2 cases. When comparing the Imaging findings with nasal endoscopy report, (Table 5), there were 3 primary key words that were looked for.

Table 5: DNE findings and CT/MRI findings.

\begin{tabular}{|c|c|c|c|c|c|c|c|c|}
\hline DNE & No. of patients & \multicolumn{3}{|c|}{ CT Scan } & \multicolumn{4}{c|}{ MRI Scan } \\
\hline & & Normal & $\begin{array}{c}\text { soft tissue thickening } \\
\text { ONLY }\end{array}$ & $\begin{array}{c}\text { Bone } \\
\text { erosion }\end{array}$ & $\begin{array}{c}\text { LoCE } \\
\text { Only }\end{array}$ & $\begin{array}{c}\text { Periantral stranding } \\
\text { ONLY }\end{array}$ & $\begin{array}{c}\text { Other } \\
\text { findings }\end{array}$ & 0 \\
\hline Normal findings & 11 & 2 & 9 & 0 & & & 0 & 0 \\
\hline Mucosal Pallor & 9 & 2 & 5 & 2 & & 1 & 1 & 0 \\
\hline Ischemic necrosis & 21 & 0 & 6 & 15 & & 5 & 7 \\
\hline
\end{tabular}

Table 6: Sensitivity of intraoperative and Imaging findings.

\begin{tabular}{|c|c|c|}
\hline Imaging finding & No. of patients & sensitivity \\
\hline CT scan & 37 & $90.20 \%$ \\
\hline $\begin{array}{c}\text { Unilateral, asymmetric soft } \\
\text { tissue thickening }\end{array}$ & 15 & $36.50 \%$ \\
\hline Bone erosion & 7 & $17.00 \%$ \\
\hline Extra sinus Spread & 13 & $76.40 \%$ \\
\hline MRI Scan & 8 & $47.00 \%$ \\
\hline Loss of Contrast Enhancement \\
(LoCE) & 6 & $35.20 \%$ \\
\hline Intra orbital involvement & 2 & $11.70 \%$ \\
\hline Intracranial involvement & 9 & $21.95 \%$ \\
\hline DNE & 21 & $51.21 \%$ \\
\hline Mucosal Pallor & & \\
\hline Ischemic changes & & \\
\hline
\end{tabular}

Normal findings noted in 11 reports, mucosal pallor noted in 9, and ischemic necrosis or eschar noted in 21 cases. The correlation between each finding and intraoperative report is shown in Table 5. Overall soft tissue thickening on CT scan was found to be the commonest finding, even though it is extremely nonspecific. It was found to correlate with abnormal findings on the initial endoscopy $76 \%$ cases. On the other hand, out of 4 scans reported normal initially 2 were found to have mucosal pallor on endoscopy. On the MRI, LoCE was the most common finding, and all patients with MRI finding of LoCE had mucosal abnormality noted on endoscopy, with necrosis being noted almost $84 \%$ cases. However, as MRI was done for specific indications, it is likely that this is a sub-group with more advanced and aggressive disease. Other studies have looked at early routine MRI as a diagnostic tool in Invasive fungal sinusitis and have reported better sensitivity [6]. Overall, CT scan Sinuses demonstrated $90 \%$ sensitivity when assessed carefully specifically looking for mucosal abnormalities, and bone erosion indicative of IFS. With CT scan sinuses and Nasal endoscopy, the sensitivity approached $95 \%$. However, it is important to note that 2 of the patients were normal on both CT scan and nasal endoscopy. MRI scans have earlier been assessed as a screening tool in IFS, and studies have found variable sensitivity of $64 \%-87 \%[6,7]$. However, in our study we found that LoCE or the so called "Black turbinate" sign is indeed associated with necrosis and tissue invasion in more than $84 \%$ cases. The Sensitivity of individual Endoscopic and Imaging findings can be found in Tables $6 \& 7$. As can be seen, when frank mucosal necrosis sets in, both CT and MRI are very effective at picking up the disease reaching almost $100 \%$ sensitivity, and their role becomes equally or even more geared towards treatment planning and staging.

Table 7: Association between DNE findings and Imaging.

\begin{tabular}{|c|c|c|c|}
\hline DNE & & & \\
\hline Pallor & 9 & Ischemia & 21 \\
\hline CT Scan & 9 & & 21 \\
\hline Normal & 2 & & 0 \\
\hline Abnormal & 7 & & 21 \\
\hline soft tissue ONLY & 5 & & 6 \\
\hline Bone erosion & 2 & & 15 \\
\hline MRI & 2 & & 15 \\
\hline Abnormal & 2 & & 15 \\
\hline LoCE & 1 & & 13 \\
\hline Periantral & 1 & & 7 \\
\hline Other findings & 0 & & 6 \\
\hline
\end{tabular}

However, in earlier disease, Nasal endoscopy may be normal in up to $55 \%$ of cases (11 out of 20 patients). However, CT scan is helpful and can increase the yield to about $80 \%$. It is very probable that MRI would also have similar or better sensitivity, as shown by other studies [6,7]. In the other sub group of patients with mucosal pallor on exam, CT scans were reported normal in up to $22 \%$ cases, and MRI which was done for only 2 patients, both were abnormal. Box 1 shows short case studies of the 2 cases where both CT scan and nasal endoscopy was reported normal. In both these cases, there was no response to Antibiotics, and the patient was found to have frank mucosal crusting on follow up Nasal endoscopy at 48 hours and 72 hours respectively. Thus, considering the higher cost of MRI vs CT scan, we propose the following diagnostic algorithm, for Invasive Fungal sinusitis. This is based on the concept of there being two subgroups i.e. one with more advanced disease in which endoscopy alone is virtually diagnostic, and Imaging is needed for assessing extent of involvement, and an early group which is much more likely to be missed by endoscopy. It is in this group, that CT scan has adjunctive value. We propose CT scan be done in all patients in the absence of necrosis and the CT scan 
is evaluated specifically for the known radiologic findings. If CT scan shows soft tissue thickening ONLY, which has been found to be extremely non-specific, we recommend starting treatment if the initial endoscopy showed mucosal pallor. On the other hand, if the initial exam was normal, then consideration must be given to re-scoping the patient and adjunct diagnostic tools like targeted biopsy, frozen section or cytology. If both CT scan and re-look endoscopy is normal, MRI can be considered in patients with mid to high clinical suspicion. In patients with very low clinical suspicion, the patient can be assessed with a nasal endoscope in 12-24 hours. We believe this would allow judicious use of the imaging modalities at hand and also allow the best possible diagnostic yields.

\section{Conclusion}

At present time, there is no standard, accepted diagnostic protocol for Acute Invasive fungal sinusitis. Various authors have proposed either using MRI as a screening tool in all patients $[6,7]$ while many other studies have shown contradictory results $[5,8,9]$. In this study we have reviewed our series of Invasive Fungal Sinusitis patients, to formulate a cost-effective, rational diagnostic protocol for this group of patients, utilizing imaging and endoscopy to the maximum benefit. Much larger studies will need to be conducted for validation of this protocol. Limitations of this study include small number of patients and lack of control group.

\section{References}

1. Kim DW, Heo ST, Jeon SY, Kim JY, Lim MH, et al. (2010) Invasive paranasal mucormycosis with peripheral eosinophilia in an immunocompetent patient. Med Mycol 48(2): 406-409.

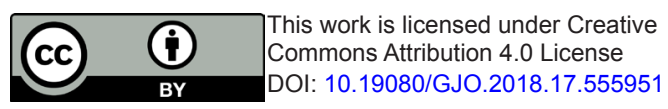

2. Gillespie MB, O'Malley BW (2000) An algorithmic approach to the diagnosis and management of invasive fungal rhinosinusitis in the immunocompromised patient. Otolaryngol Clin North Am 33(2): 323334.

3. Wang M, Lv D, Huang S (2014) [The diagnosis and treatment progress of invasive fungal sinusitis]. Lin Chung Er Bi Yan Hou Tou Jing Wai Ke Za Zhi. 28(11): 832-834, 836.

4. Walsh TJ, Anaissie EJ, Denning DW, Herbrecht R, Kontoyiannis DP, Marr KA, et al. (2008) Treatment of aspergillosis: clinical practice guidelines of the Infectious Disease Society of America. Clin Infect Dis 46(3): 327360

5. DelGaudio JM, Swain RE Jr, Kingdom TT, Muller S, Hudgins PA (2003) Computed tomographic findings in patients with invasive fungal sinusitis. Arch Otolaryngol Head Neck Surg 129(2): 236-240.

6. Groppo ER, El-Sayed IH, Aiken AH, Glastonbury CM (2011) Computed tomography and magnetic resonance imaging characteristics of acute invasive fungal sinusitis. Arch Otolaryngol Head Neck Surg 137(10): 1005-1010.

7. Howells RC, Ramadan HH (2001) Usefulness of computed tomography and magnetic resonance in fulminant invasive fungal rhinosinusitis. Am J Rhinol 15(4): 255-261.

8. DelGaudio JM, Clemson LA (2009) An early detection protocol for invasive fungal sinusitis in neutropenic patients successfully reduces extent of disease at presentation and long term morbidity. Laryngoscope 119(1): 180-183.

9. Silverman CS, Mancuso AA (1998) Periantral soft-tissue infiltration and its relevance to the early detection of invasive fungal sinusitis: CT and MR findings. AJNR Am J Neuroradiol 19(2): 321-325.

\section{Your next submission with Juniper Publishers will reach you the below assets}

- Quality Editorial service

- Swift Peer Review

- Reprints availability

- E-prints Service

- Manuscript Podcast for convenient understanding

- Global attainment for your research

- Manuscript accessibility in different formats

( Pdf, E-pub, Full Text, Audio)

- Unceasing customer service

Track the below URL for one-step submission https://juniperpublishers.com/online-submission.php 